\title{
The Game Analysis of Development Investment Mode Selection in Lower Permeability Oilfield
}

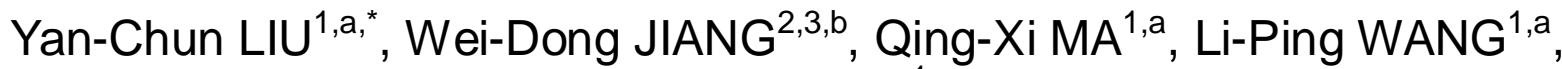 \\ Jian-Jun YAN ${ }^{1, a}$ \\ ${ }^{1}$ Daqing technician college, Daqing, Heilongjiang 163255, China \\ ${ }^{2}$ School of Management, Harbin Institute of Technology, Harbin, Heilongjiang 150001, China \\ ${ }^{3}$ Hailar-Tamtsag Headquarters of Daqing Oilfield Co.,Ltd. Hulunbuir, Inner Mongolia 021008, China \\ aliuyanchunzy@126.com, jiangweidong@petrochina.com.cn \\ ${ }^{*}$ Corresponding author
} Keywords: Lower Permeability Oil Fields; Oil Field Development; Investment Mode; Choice of
Model; Game Theory

\begin{abstract}
A commissioned development and cooperative development is the main and commonly used form of foreign lower permeability oilfield development. In the case of information asymmetry, in the process of cooperation and game, permeability, recovery rate and yield are all elements and the interests of both parties concerned. It shows that cooperation can be reached regardless of the high and low permeability by constructing the selective model . When the probability of high permeability is greater, resources development party more like to take entrustment and transfer mode; if the probability of low permeability is greater, resources development party more like to take joint development mode in the lower permeability oilfield. What model, their respective predicted permeability, expected returns, reservation utility and so on are the Influencing factors.

The development of an oil block involve both the resources development party and the resources owner. These owners can develop resources by themselves or commission them to others: Transferring the concession mining title of oil block to the developers for only a limited number of years by use of an agreement. Then the developers are in charge of the developing as well as receive compensation and the owner will take over the oil block when it achieve payback period of resources. In addition to these two methods, there still another method for the owners of resources: Both sides make joint contribution under a certain proportion, cooperatively develop the oil field and obtain a share of return. In the case of the commissioned development form, the owner of the resources (denoted as Party A)require the resources development party(denoted as Party B) to make efforts to increase the permeability and recovery ratio; under the cooperated development form, party A require the development ability of party B is better than that of party $\mathrm{A}$ in order to extend the exploitation year (which means sustainable oilfield development) and increase the interests of party A continuously. For this reason, regardless of whether commissioned development or cooperative development, both sides have common benefits in terms of increasing permeability, recovery ratio and output. In view of the practical situation, most of the oil field exploited at present are lower permeability oil fields and the level of permeability is an significant factor for these oil fields: the higher of the permeability, the less cost of increasing the output and of improving the recovery ratio, and vise versa.
\end{abstract}

\section{The construction of the selective model of investment and development method of lower permeability oil fields}

At present, mathematical model of investment mode of lower permeability oil fields are difficult to retrieval in existent literature. Since there are some similarity between investment mode of lower permeability oil fields and cooperative mode of combining learning with research and production, mathematical model of investment mode of lower permeability oil fields can be constructed through 
remolding relevant cooperative mode of combining learning with research and production in order to resolve the issue of model building.

Suppose the return determined by permeability and recovery ratio is an increasing function of oil development ability, which means $\pi=\pi(\rho) \quad$ and $\quad \pi\left(\Omega \triangleright \pi\left(\rho_{1}\right)\right.$

When we act commissioned development, suppose the land granting price of oil block is $\mathrm{P}$. If the commissioned block has high permeability, the return of party A within bail able period is $\mathrm{p}$, the return of party $\mathrm{B}$ within bail able period is $\pi\left(\rho_{2}\right)-P-C_{h}$. If the commissioned block has low permeability. There is no change for the return of party $\mathrm{A}$, however, the return of Party $\mathrm{B}$ become $\pi\left(\rho_{2}\right)-P-C_{l}$. It can be seen that, in terms of Party $\mathrm{B}$, the return of oil block with high permeability is greater than that of block with low permeability.

When we act cooperative development, suppose the proportion of the investment contributed by party $\mathrm{A}$ is $\mathrm{M}$ of the whole investment of lower permeability oil fields and the proportion of party $\mathrm{B}$ will be 1-M. Then Party A can have R proportion of future return while, the proportion of the return for Party $\mathrm{B}$ is $1-\mathrm{R}$. The improvement of oil field development ability result from the increasing of recovery ratio for both sides are $\rho_{1} \cup \rho_{2} \rho_{2} \cup \rho_{2}$ respectively. It is obvious that $\left(\rho_{2} \cup \rho_{2}\right)>\left(\rho_{1} \cup \rho_{2}\right)$. When the recovery ratio of lower permeability oil fields is high, the return for party $\mathrm{A}$ is $R \pi\left(2 \rho_{2}\right)-M C_{h}$, the return for Party B is $(1-R) \pi\left(2 \rho_{2}\right)-(1-M) C_{h}$ When the recovery ratio of lower permeability oil fields is low, the return for Party A is $R \pi\left(\rho_{1} \cup \rho_{2}\right)-M C_{l}$ and the return for Party $\mathrm{B}$ is $(1-R) \pi\left(\rho_{2} \cup \rho_{2}\right)-(1-M) C_{l} .1$

In the event of both commissioned development and cooperative development are failures. Party A can only develop the oil block independently. When the permeability is high, the return for Party A is $\pi\left(\rho_{1}\right)-C_{h}$, and the return become $\pi\left(\rho_{1}\right)-C_{l}$ when the permeability is low.

In the process of cooperative development of lower permeability oil fields, both sides do not considered their coefficient of risk aversion. That is to say, they do not care for their own cost of risk. Generally speaking, it is party A who state the modality for co-operation and the only thing which party B can do is to express support view or oppose view for the cooperation modality.

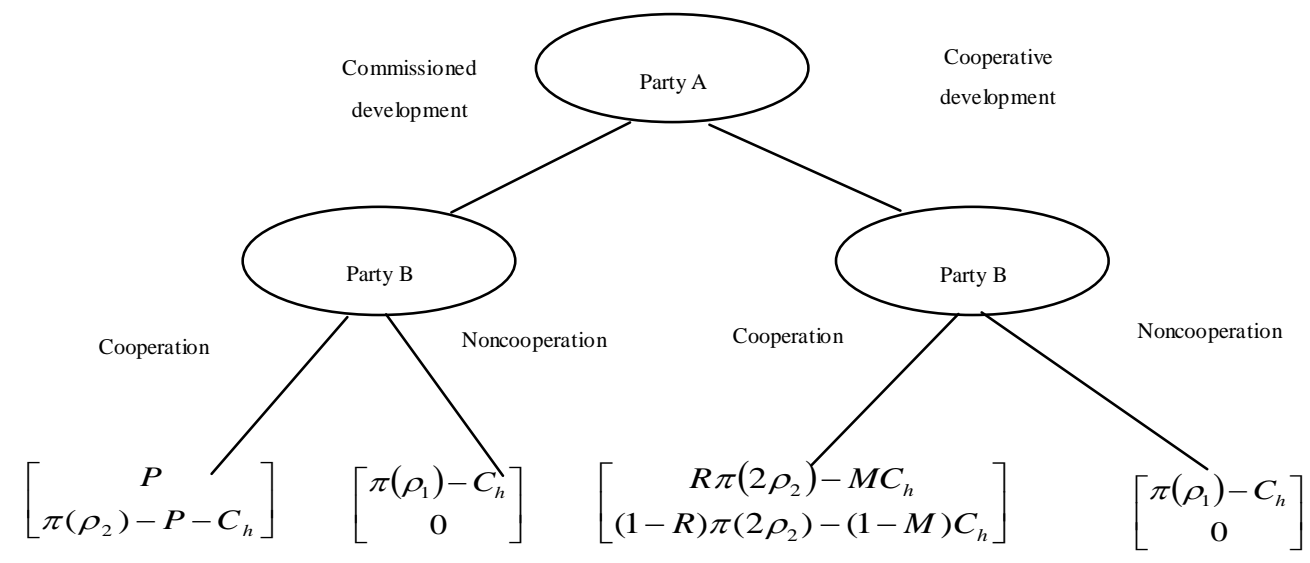

1-1 the game tree of cooperation model of developing low permeability oil fields with high permeability 


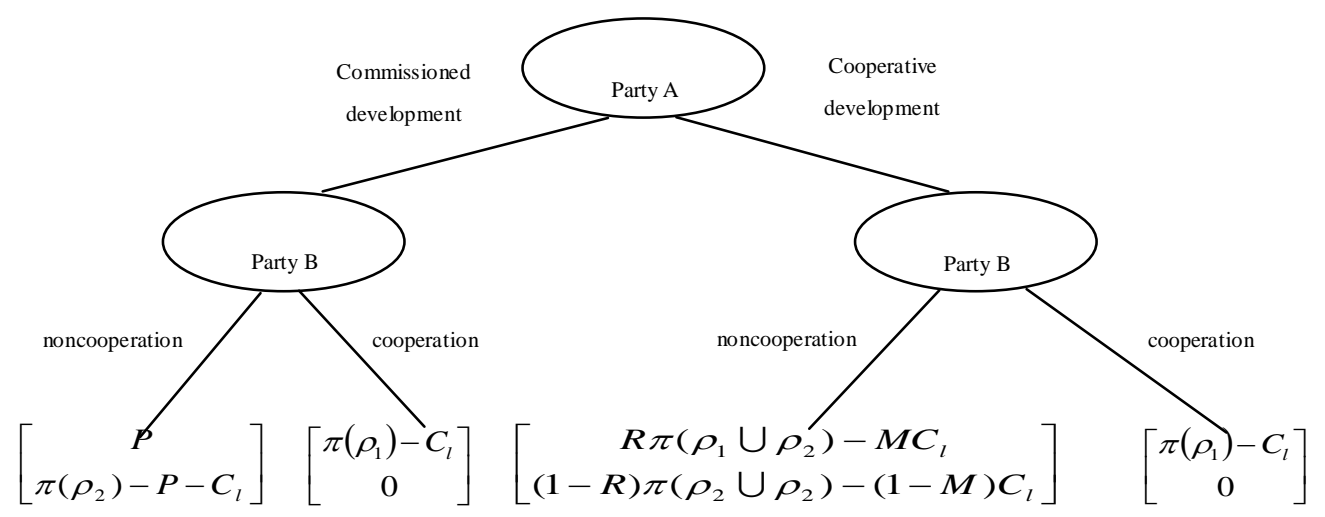

1-2 the game tree of cooperation model of developing low permeability oil fields with low permeability

According to the assumption, it can be known that $\pi\left(2 \rho_{2}\right)>\pi\left(\rho_{1} \cup \rho_{2}\right)>\pi\left(\rho_{2}\right)>\pi\left(\rho_{1}\right)$, the game process for both sides in the case of high permeability and low permeability are shown in the diagram1-1 and 1-2 respectively, and are denoted as $\left[\begin{array}{l}\text { the benefit of Party A } \\ \text { the benefit of Party B }\end{array}\right]$

As a matter of fact. the true circumstance of oilfield geology can not be reflected comprehensively and truly only by geological exploration information, which indicates an game progress under incomplete information. The probability of high permeability is ụ by reference, and the probability of low permeability is 1-u , the expected return of accepting commissioned development project for arty $\mathrm{B}$ is

$$
E\left(w_{1}\right)=u\left[\pi\left(\rho_{2}\right)-P-C_{h}\right]+(1-u)\left[\pi\left(\rho_{2}\right)-P-C_{l}\right]
$$

\section{The mathematical model for commissioned development form}

$$
\text { If } u>\frac{\pi\left(\rho_{2}\right)-p-(1-R) \pi\left(\rho_{1} \cup \rho_{2}\right)-M C_{l}}{(1-R)\left[\pi\left(2 \rho_{2}\right)-\pi\left(\rho_{1} \cup \rho_{2}\right)\right]+M\left(C_{l}-C_{h}\right)} \text {, then } E\left(w_{1}\right)>E\left(w_{2}\right) \text { and party B will accept the }
$$

commissioned development project put forward by party A

In terms of party A, they can judge the circumstance of the lowest permeability of oil block according to the exploration and development information. The mineral rights and the development value of oil field can be shown as the reserved utility of party $A$ (denoted as $S$ ).It can be judge obviously that both sides can come to an agreement as long as the price raised by party B is not below the reserved utility $\mathrm{S}$ when the transfer price of oil mineral rights proposed by Party A is $\mathrm{P}$. Otherwise, both sides can not reach the cooperation intention.

If the oil mineral rights transfers from party B to party A successfully, for Party A, it must be true that the benefit of cession is greater than the return from developing oil field independently. Otherwise, party A will develop the oil field by themselves. If they adapt the transfer strategy, the transfer price could be confirmed within the range of follows: $S \leq P \leq \pi\left(\rho_{2}\right)-\pi\left(\rho_{1}\right)-(1-u)\left(C_{l}-C_{h}\right)$. 1-u become smaller as $\mathrm{u}$ increase, result in the decreasing of $(1-u)\left(C_{l}-C_{h}\right)$ and $\mathrm{p}$ become larger. That is to say, the larger probability of high permeability, the higher transaction value of party A, vice versa.

The reserved utility $S$ is unknown and difficult to predict for party $B$ since it is the hidden information of party A. Therefore, when both sides are defining the transfer price, party B are do their best to let Party A know the significance of knowing the level of permeability for developing lower permeability oil fields. At the same time, party A also signal intentionally that there are numerous buyers under the basic data of permeability which obtained through exploration and development, that the market outlook can be very promising and that they may take more methods 
of exploration and development to achieve the goal of improving the reserved utility $\mathrm{S}$.

If Party B detect the permeability is low, according to the return function, party A would do their best to transfer the lower permeability oil fields as long as the price raised by party A is lower than received utility S. For Party B, if the permeability is low, it would be unwise to accept the oil mineral rights. For this reason, judging the level of permeability and the cooperation approach is significance. In order to maximizing the owner utility, party A will try by every means to judge the level of permeability by improving the exploration and development ability and make the investment decision more scientific and reasonable.

\section{The mathematical model of cooperated development}

If $u<\frac{\pi\left(\rho_{2}\right)-p-(1-R) \pi\left(\rho_{1} \cup \rho_{2}\right)-M C_{l}}{(1-R)\left[\pi\left(2 \rho_{2}\right)-\pi\left(\rho_{1} \cup \rho_{2}\right)\right]-M\left(C_{h}-C_{l}\right)}$, then $E\left(w_{1}\right)<E\left(w_{2}\right)$ and Party B will accept the cooperated development from put forward by Party A.

For Party B, when the permeability of low permeability oil field is high, as long as they receive more return from the cooperated form than the return from developing oil field by themselves independently. Which means $(1-R) \pi\left(2 \rho_{2}\right)-(1-M) C_{h} \geq \pi\left(\rho_{1}\right)-C_{h}$ and ${ }_{R \leq} \frac{M C_{h}-\pi\left(2 \rho_{2}\right)-\pi\left(\rho_{1}\right)}{\pi\left(2 \rho_{2}\right)}$, party $\mathrm{B}$ will agree to the cooperated development model. At the same time, the allocation proportion (denoted as 1-R) can not exceed the upper limit of acceptable range of Party A. Which means

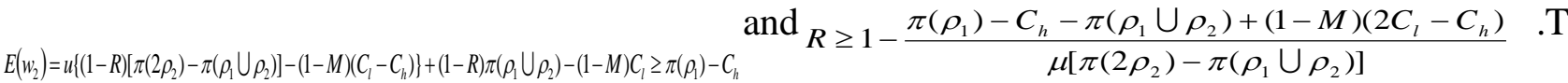
herefore, the range of partition ratio is as follows $1-\frac{\pi\left(\rho_{1}\right)-C_{h}-\pi\left(\rho_{1} \cup \rho_{2}\right)+(1-M)\left(2 C_{l}-C_{h}\right)}{\mu\left[\pi\left(2 \rho_{2}\right)-\pi\left(\rho_{1} \cup \rho_{2}\right)\right]} \leq R \leq \frac{M C_{h}-\pi\left(2 \rho_{2}\right)-\pi\left(\rho_{1}\right)}{\pi\left(2 \rho_{2}\right)}$

And both sides will decide the partition ratio within this range, the more narrow of the range of $\mathrm{R}$, the more likely for both sides to adapt the cooperated strategy. In terms of the actual situation of development of Lower Permeability Oil Fields, when Party A itself has high level of oilfield exploiting ability, party B would has strong aspiration to cooperate with party A as long as exploiting ability of Party B is better than that of party A, which means less risk and more fluently of exploiting oil block.

When the permeability is low, for party A, as long as the return from cooperation exceed the return from exploiting independently, which means $R \pi\left(\rho_{1} \cup \rho_{2}\right)-M C_{l}>\pi\left(\rho_{1}\right)-C_{l}$ and $R>\frac{\pi\left(\rho_{1}\right)-(1-M) C_{l}}{\pi\left(\rho_{1} \cup \rho_{2}\right)}$, party $\mathrm{A}$ is willing to cooperate with party $\mathrm{B}$, and party $\mathrm{B}$ also has this willingness in the case of partition ratio $\mathrm{R}$ is greater than 0 . However, neither party A nor party $\mathrm{B}$ can easily know the definite level of permeability. The partition ratio $\mathrm{R}$ can only be determined by the expected return.

\section{The conclusion and revelation of the selective model of investment and development method} of lower permeability oil fields

\section{Conclusion}

(1)The larger probability of high permeability of oil block, the more likely for party B to take commissioned development strategy, and the cooperation can be achieved as the transfer price of mining rights is in the range of $S \leq P \leq \pi\left(\rho_{2}\right)-\pi\left(\rho_{1}\right)-(1-u)\left(C_{l}-C_{h}\right)$.

(2)The larger probability of low permeability of oil block, the stronger willingness for party B to take cooperated development form so that lower the development risk and the cooperation can be achieved when the partition ratio is in restricted regions as follows $1-\frac{\pi\left(\rho_{1}\right)-C_{h}-\pi\left(\rho_{1} \cup \rho_{2}\right)+(1-M)\left(2 C_{l}-C_{h}\right)}{\mu\left[\pi\left(2 \rho_{2}\right)-\pi\left(\rho_{1} \cup \rho_{2}\right)\right]} \leq R \leq \frac{M C_{h}-\pi\left(2 \rho_{2}\right)-\pi\left(\rho_{1}\right)}{\pi\left(2 \rho_{2}\right)}$

It has great disadvantages if exploit oil field by commissioned development. At present, no country take the strategy that transfer mining rights once only to exploit oilfield .but obtain the 
transfer compensation through gain sharing method, and in this way, they can get profit for long term.

\section{Revelation}

A commissioned development and cooperative development is the main used form of lower permeability oilfield development all over the world. Based on the game analysis quantitatively of both sides, it is obvious that the choose process of cooperation form for lower permeability oil fields is an game process. After discuss the exploiting ability of oil field of both sides and the effects of the ability to the cooperation form. We can find that the cooperative process must exist adverse selection which affect the willingness of cooperation for party $\mathrm{B}$ in consideration of the asymmetry information. However, it is just the asymmetry information that open the door for cooperation of both sides even though the permeability of oil field is low. For this reason, on one hand, it can have positive effect for the cooperated development form of party $\mathrm{B}$, since there are various uncertainty in the process of exploiting the lower permeability oil fields and party B will also require party A to take the risk of development when the permeability, recovery ratio and output are low. On the other hand, under the existence of asymmetry information .in the process of exploiting lower permeability oil fields, the serious situation that the output of oil productions declined heavily and the recovery ratio become too low would happen if party B pursue production in the wrong perspective regardless of objective condition and if party B pursue short term return with damaging the interest of Party A. Party A is not like to see this consequence, therefore, it would require party $\mathrm{B}$ to make rational use of consultants from party A, constructing technology and engineering ability so that monitor the behaviors of Party B.

The choice of investment form of lower permeability oil fields is the first step on the road to success of the cooperation. A commissioned development is commons in the course of international oilfield development cooperation and the cooperated development is also account for a large proportion. Party A can improve its own ability of oil field exploitation when they adopt the cooperated development method and its ability will improve slowly if party A mainly rely on the commissioned development .

\section{Reference}

[1] Liping Wang, Qingxi Ma, Hongyan Xu, Dapeng Liang(2009) The game mode selection for development cooperation between enterprise and university. Journal of Daqing Petroleum Institute Vol.33 No.1 Feb 2009

[2] Hailin Liu(2006)The game analysis of industry-university-research cooperation. The dissertation for master degree in Wuhan University of Technology 2006,(10):34-38 